Volume 17, n. 4, ano, 2021

\title{
O desmantelamento dos cursos de licenciaturas da Universidade Estadual de Goiás ante as políticas autoritárias de governos
}

\section{Francilane Eulália de Souza ${ }^{1}$}

Resumo O objetivo deste artigo é analisar e criticar as consequências da crise que a Universidade Estadual de Goiás (UEG) vem enfrentando nos últimos anos, particularmente o fechamento de cursos de licenciatura. Nesse contexto, apresentamos os processos que desencadearam tal crise e os seus efeitos, e, ainda, apontamos como o Exame Nacional de Desempenho de Estudantes (ENADE), com suas perspectivas no processo de avaliação e qualificação das IES, vem contribuindo para o desmantelamento dos cursos de licenciaturas na UEG. Para tanto, realizamos pesquisa bibliográfica e documental, processo em que foram de suma importância as análises das legislações instituídas e de seus relatórios institucionais. Embora a crise da UEG seja um processo ainda em curso, podemos inferir que o fechamento dos seus cursos de licenciatura tem ocorrido dentro de um contexto de truculência e autoritarismo, colocando em questão a autonomia da UEG e, acima de tudo, o direito à educação superior pública no estado de Goiás.

Palavras chaves: Licenciatura. Autonomia. Universidade.

\section{The dismantling of degree courses at the State University of Goiás in view of the authoritarian policies of governments}

\begin{abstract}
The purpose of this article is to analyze and criticize the consequences of the crisis that the State University of Goiás has been facing in recent years, particularly the closing of degree courses. In this context, we present the processes that triggered this crisis and its effects, and also point out how the ENADE (National Student Performance Exam), with its perspectives in the HEI evaluation and qualification process, has contributed to the dismantling of degree courses at the State University of Goiás. For this purpose, we carried out bibliographic and documentary research, a process in which the analyzes of the legislation instituted by UEG and its institutional reports were extremely important. Although the UEG crisis is still an ongoing process, we can infer that the closure of its degree courses has occurred within a context of truculence and authoritarianism, calling into question the autonomy of UEG and, above all, the right to superior education public in the state of Goiás.
\end{abstract}

Keywords: Degree courses. Autonomy. University.

\section{INTRODUÇÃO}

É mister considerar que a universidade como instituição social está em constante movimento, logo, o exercício de pensar sobre ela exige contínua reflexão. Nesse processo, conclusões são parte de um todo em movimento. No estado de Goiás, a Universidade Estadual

\footnotetext{
${ }^{1}$ Profa. Dra. do departamento de Geografia da UEG câmpus Nordeste. E-mail: francilanee@ @otmail.com
} 


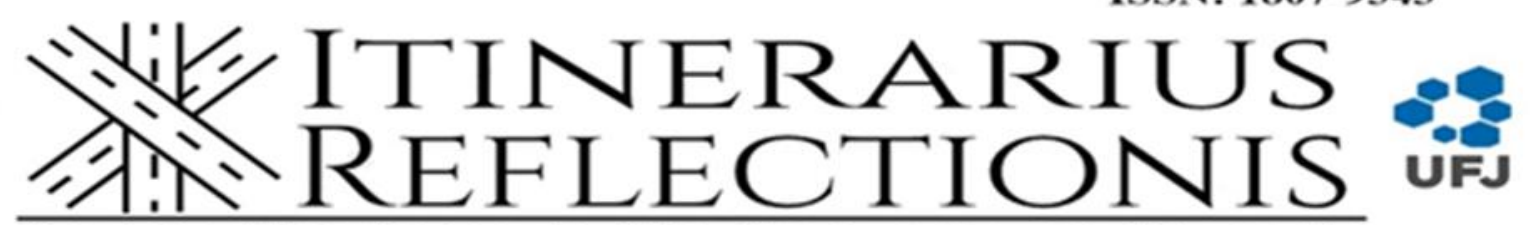

Revista Eletrônica da Pós-Graduação em Educação Universidade Federal de Jataí

Volume 17, número 4, ano 2021.

de Goiás vem sendo submetida a constantes mudanças: muda-se o governo, muda-se a UEG. Nesse contexto, a incerteza, a falta de inteireza no caminhar dessa instituição é a mesma incerteza quanto ao caminhar das políticas do governo. Assim, a luta por uma universidade pública, gratuita, de qualidade e autônoma é pauta antiga e constante nessa instituição.

A Universidade Estadual de Goiás foi fundada em abril de 1999 a partir do processo de transformação da Universidade Estadual de Anápolis (UNIANA) e da incorporação de Instituições de Ensino Superior (IES) isoladas. Até 2019, a Universidade Estadual de Goiás era constituída por 41 campi universitários, um Centro de Ensino e Aprendizagem em Rede - CEAR e 24 Polos de Educação à Distância (EaD) espacializada em 39 municípios do estado de Goiás.

Atualmente, por meio de intervenção do estado, que impeliu a reforma administrativa na UEG, esta passou a ter oito campi. A análise do relatório de reestruturação da UEG de 2019 evidencia que os cursos de licenciatura vêm passando por um processo de desmantelamento vindo de cima para baixo. Até o momento, 21 cursos de licenciatura estão em processo de fechamento, dentre os quais dois cursos de Geografia. Assim, acirra-se a luta pela democracia, pela autonomia e pela sobrevivência das licenciaturas na UEG.

O objetivo deste artigo é analisar as consequências da crise que a UEG vem enfrentando nos últimos anos, particularmente o fechamento de cursos de licenciatura. Nesse contexto, apresentamos os processos que desencadearam tal crise e os seus efeitos, particularmente nos cursos de Geografia, bem como, apontamos como o Exame Nacional de Desempenho de Estudantes (ENADE) e suas perspectivas de consolidação no processo de avaliação e qualificação das IES vem contribuindo para o desmantelamento dos Cursos de licenciaturas da Universidade Estadual de Goiás. Vale destacar, também, que o ENADE é campo fértil para as polícias de contingenciamento de recursos pelas quais as IES Brasileiras vêm passando, e, por isso, também é instrumento fartamente utilizado para justificar o fechamento de cursos superiores em outras instituições no Brasil.

Este artigo, é acima de tudo, uma oportunidade para refletir sobre o contexto de crise em que se encontra a UEG no momento atual. Como se trata de um processo ainda em curso, este é também um momento tenso, conflituoso, e acima de tudo incerto. Adotar um olhar de fora para quem está dentro desse processo, não obstante necessário, é extremamente 


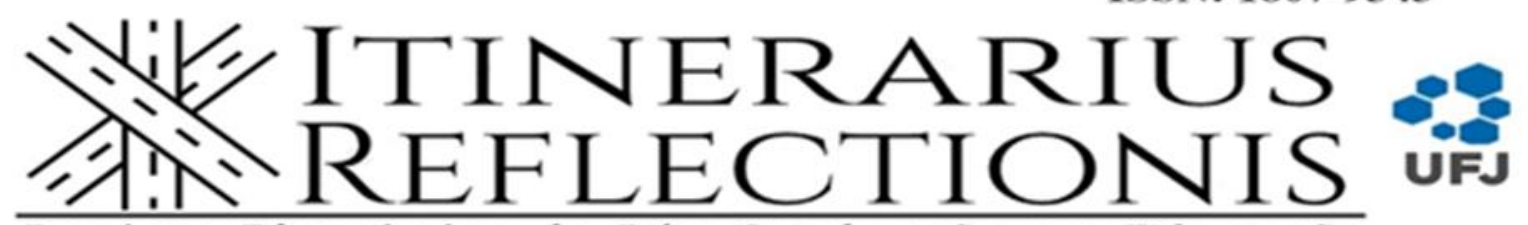

Revista Eletrônica da Pós-Graduação em Educação

Universidade Federal de Jataí

Volume 17, número 4, ano 2021.

difícil; ainda assim, precisamos aprender a contar nossa própria história. Nesse contexto, este artigo trará contribuições para se pensar na importância da autonomia da universidade pública e no seu papel enquanto instituição cuja formação prioriza a dimensão humanista.

\section{A METODOLOGIA DA PESQUISA}

A pesquisa apresentada é acima de tudo uma pesquisa qualitativa em educação, afinal, nosso objeto de pesquisa é a universidade, e a compreensão de instantes da mesma nos ajuda a pensar também nos rumos que a educação que se faz nessa instituição pode tomar.

Fazer essa pesquisa não tem sido tarefa fácil, afinal, como já apontamos, nosso objeto de pesquisa está em movimento. Ademais, são tantas questões políticas, administrativas, acadêmicas que vêm ocorrendo na UEG, que nos levam a fazer recortes metodológicos, reduções sobre o que de fato investigar, logo, certamente não conseguiremos apontar todas as consequências advindas da crise que assola essa instituição.

A princípio, essa pesquisa foi fundamentada por bibliografias que nos permitem pensar a universidade no Brasil a partir do princípio da autonomia e do seu papel perante a sociedade, visto que, acima de tudo, esta desempenha importante função junto ao direito à educação. Buscamos, ainda, outras pesquisas ligadas à crise que a UEG vem enfrentando, pois, embora ainda sejam escassas, nos preocupamos em fundamentar teoricamente nossa pesquisa a partir de diálogo com outros pesquisadores. ${ }^{2}$

Realizamos, também, pesquisa documental em arquivos públicos da UEG, particularmente documentos oficiais (Decretos, Resoluções, Instruções Normativas, etc.) e relatórios oficiais, como os de avaliação institucional e os de redesenho. Tomamos o cuidado de averiguar a suplantação de informações, assim como a revogação das legislações aqui pesquisadas. Realizamos ainda pesquisa quali-quantitativa nos sites oficiais do Instituto

\footnotetext{
2 Nesse processo foi de suma importância o artigo do professor Wilson Lopes de Souza intitulado de "Harmonização e unificação das matrizes curriculares: "curso de Geografia" realizado a partir de debates e contribuições de professores do curso de Geografia do campus Nordeste da UEG. Também, foi importante o artigo das professoras Luciana Nogueira da Silva e Maria Eneida da Silva intitulado de "O mapa do retrocesso da interiorização da educação superior: a redução da Universidade Estadual de Goiás”.
} 


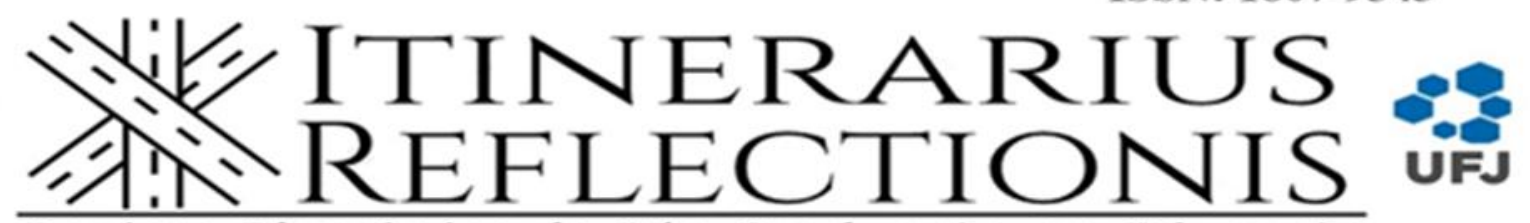

Revista Eletrônica da Pós-Graduação em Educação

Universidade Federal de Jataí

Volume 17, número 4, ano 2021.

Nacional de Estudos e Pesquisas Educacionais Anísio Teixeira (INEP) com objetivo de acessar os relatórios do ENADE e do Sindicato Nacional dos Docentes das Instituições de Ensino Superior (ANDES). Outra fonte de nossas pesquisas foram cartas abertas dos dirigentes da UEG e entrevistas com os sujeitos envolvidos, coletadas em jornais on-line de empresas de comunicação do estado de Goiás. Nesse processo, tomamos também o cuidado de verificar a autenticidade dos documentos analisados.

Ainda, consideramos as pesquisas que realizamos anteriormente sobre componentes pedagógicos na UEG, nos últimos 15 anos, o que nos levou a pensar o mesmo a partir das adversidades dessa universidade. As orientações de Trabalho de Conclusão de Curso (TCC) e de especialização, também, contribuíram para as análises aqui apresentadas.

\section{RESULTADOS}

\subsection{Nasce uma Universidade em Goiás alicerçada nas licenciaturas: "a menina dos olhos" do ex-Governador Marconi Perillo}

A universidade pública brasileira, que, a priori, era percebida e sentida como espaço de produção de conhecimento novo, precisa ser também reconhecida como outros espaços: o de socialização de cultura, de reconhecimento de classe, de direitos sociais, enfim, espaço de luta pela democracia, pela autonomia, pela ampliação de direitos, ocupando, entre as classes menos favorecidas, a oportunidade para ampliar o direito ao ensino público. Ainda, mais que lugar para "formar" pessoas para inseri-las no mundo do trabalho, a universidade pode ser apropriada para ressignificar o saber numa perspectiva de constituição do sujeito crítico, reflexivo e atuante.

Ainda, a universidade pública é uma instituição social e, como tal, deve refletir os anseios da sociedade. Entretanto, como nos lembra Chaui (2003, p.6), “[...] a relação entre universidade e Estado também não pode ser tomada como relação de exterioridade, pois o caráter republicano e democrático da universidade é determinado pela presença ou ausência da prática republicana e democrática no Estado".

Nesse contexto, no estado de Goiás, a UEG nasce com objetivos atrelados à 


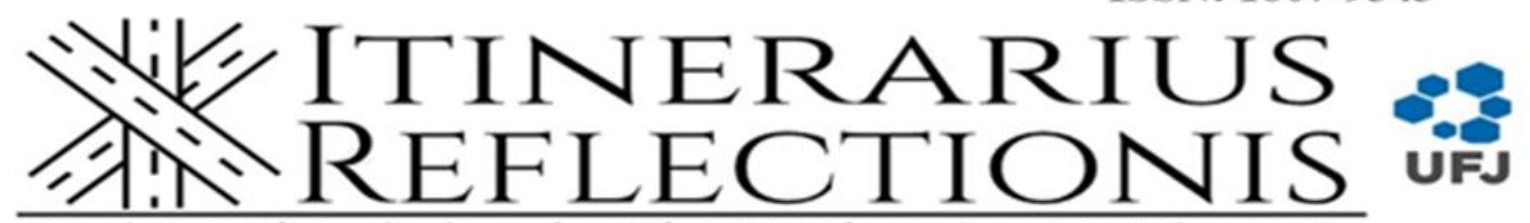

Revista Eletrônica da Pós-Graduação em Educação

Universidade Federal de Jataí

Volume 17, número 4, ano 2021.

política de seu idealizador, o ex-governador Marconi Perillo. Se, a princípio, essa instituição nasce visando à interiorização do ensino público superior em Goiás, ao longo do tempo, esses objetivos se perderam em meio às políticas e interesses do governo.

A Universidade Estadual de Goiás foi fundada pela Lei nº13. 456, de 16 de abril de 1999, a partir do processo de transformação da Universidade Estadual de Anápolis (UNIANA) e da incorporação das 28 Instituições de Ensino Superior (IES) isoladas, mantidas pelo poder público estadual. Até 2019, a Universidade Estadual de Goiás era constituída por 41 campi universitários em 39 municípios do estado de Goiás, tendo como sede a Unidade de Anápolis. Em toda a UEG, eram oferecidos 171 cursos de graduação, sendo em sua maioria cursos de licenciatura (84), dos quais 10 eram de Licenciatura Plena em Geografia. Segundo relatório de avaliação institucional, existiam "40 cursos de Pós Graduação Lato Sensu (Especialização) e 16 cursos de Pós Graduação Stricto Sensu, sendo 14 mestrados e 2 doutorados" (UEG-RELATÓRIO INSTITUCIONAL, 2019, p.9). Quanto ao ensino pesquisa e extensão, em 2019, podemos pontuar que havia:

(...) 515 projetos de extensão, distribuídos nos 41 Campus da UEG. Foram protocolados, avaliados e aprovados na Pró-reitoria de Pesquisa e Pósgraduação, 598 projetos de pesquisa de docentes da UEG, distribuídos nos diversos Campus e foram desenvolvidos 05 projetos de ensino em 04 Campus dessa universidade (UEG, RELATÓRIO INSTITUCIONAL, 2019, p. 8).

Embora esses números sejam significativos, vale destacar que não há política de financiamento dos projetos de pesquisa e de extensão na UEG, e que eles são realizados, muitas vezes, sem a participação de bolsistas, visto que a quantidade de bolsas é insatisfatória para atender a todos os projetos.

Desde sua criação até o ano de 2019 essa Universidade estava buscando mecanismos para se consolidar enquanto tal, tendo ampliado tanto o quadro de servidores efetivos como os programas de pós-graduação. Foi implementada bolsa permanente para alunos, bem como bolsas de incentivos aos pesquisadores, dentre outras ações. No entanto, apesar de seus esforços, a UEG ainda enfrenta diversas dificuldades para se manter no cenário educacional brasileiro, o que se deve, em parte, ao seu papel no cenário político- 


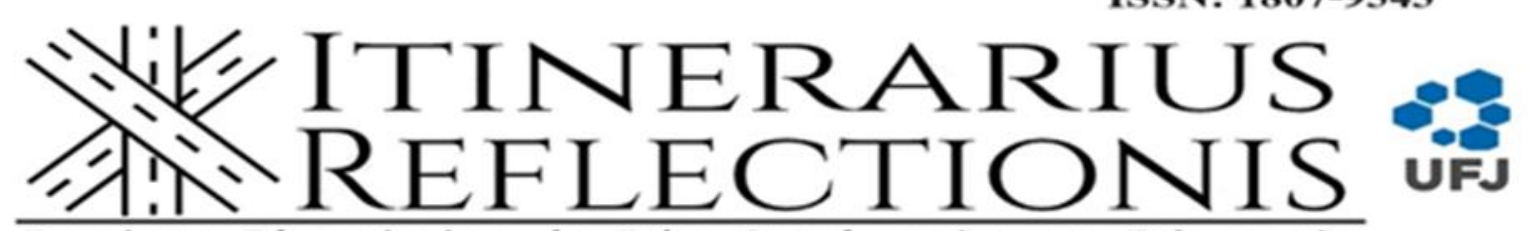

Revista Eletrônica da Pós-Graduação em Educação Universidade Federal de Jataí

Volume 17, número 4, ano 2021.

governamental, que ora a coloca à disposição das políticas do estado, ora das políticas do governo. Dentre estas, se destacam negativamente a expansão dos campi universitários a partir de 2006.

Podemos citar alguns problemas mais pontuais, como a infraestrutura precária da Universidade desde sua constituição. A UEG foi estabelecida em prédios pensados apenas para abrigar salas de aula, de modo que, não raro, os campi não possuem espaços para atividades práticas como laboratórios, orientação de alunos, exercícios de pesquisa e extensão, chegando ao ponto de, em alguns casos, sequer haver sala de professores e coordenadores. Os espaços das bibliotecas são insuficientes até para abrigar o acervo bibliográfico que, por sua vez, também é insuficiente para se pensar um ensino de qualidade. A maioria das bibliotecas não consegue atender nem mesmo as bibliografias básicas dos cursos.

Aos problemas supracitados soma-se, ainda, a deterioração da infraestrutura já existente. Não obstante, em função do quantitativo de campi, alguns vêm se destacando por abrigar uma infraestrutura com menos problemas.

Em se tratando de gestão, até 2012 a UEG foi dirigida por Reitores que faziam parte do quadro temporário comissionado, fato muito comum nos campi que também eram dirigidos por diretores do quadro de temporário, muitos com apenas especialização. Até o momento, no entanto, essa prática parece ter sido freada por meio de resolução própria da UEG.

Outro fato preocupante diz respeito aos servidores que eram, até 2019, em sua maioria, do quadro de temporários, como destacado no portal de transparência do estado de Goiás no ano de 2018, que aponta que, dos 3.898 servidores, 1.653 são efetivos e 1.862 são temporários, sendo que, destes, aproximadamente 1.600 exerciam o cargo de professor, de modo que mais de $40 \%$ dos docentes possuíam regime de trabalho em contrato temporário. 78 docentes em regime de contrato temporário possuíam apenas graduação, e mais de $50 \%$ dos professores contratados possuíam apenas especialização. Um fato que agravava ainda mais essa questão é que, a despeito de os contratos temporários serem renovados a cada três anos, estes não precisavam ser interrompidos, e nenhum afastamento era requerido, logo, era possível encontrar docentes com 19 anos atuando em sala na UEG, o que criava, para eles, uma falsa expectativa de direitos que, de fato, não lhes eram garantidos por lei. 


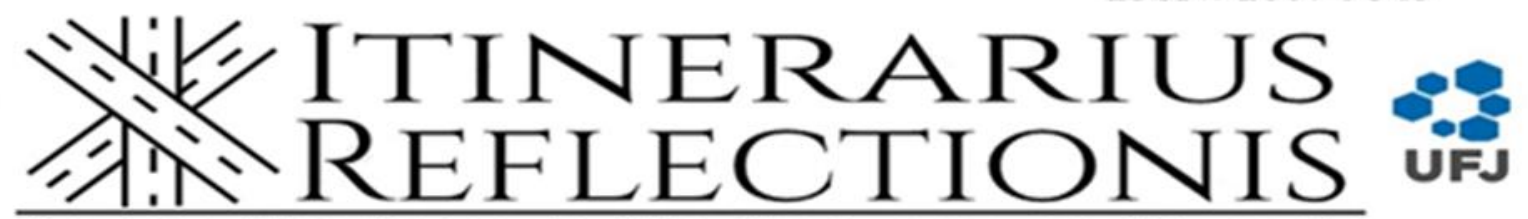

Revista Eletrônica da Pós-Graduação em Educação

Universidade Federal de Jataí

Volume 17, número 4, ano 2021.

Sobre essa questão, Favero (2004) aponta que:

[...] uma universidade sem laboratórios, com bibliotecas precárias e, sobretudo sem o indispensável pessoal qualificado - professores e alunos em tempo parcial, ou professores horistas - para a produção do conhecimento, para a elaboração de pensamento e a invenção de mecanismos originais, o ensino tende a se tornar estéril e obsoleto (p. 56).

No ano de 2016, a UEG, por meio da atual Reitoria, anunciou uma reestruturação de cursos por meio do que foi chamado de Redesenho Institucional. Assim,

Com o significativo número de vagas ociosas e baixa demanda em várias unidades, é preciso reconfigurar o portfólio de cursos, ajustando-os de forma mais adequada às demandas qualificadas locais e regionais. Neste sentido, $o$ Conselho Universitário aprovou a substituição de um total de 8 cursos de graduação, com destaque para a implantação do curso de Medicina Veterinária, no Câmpus São Luís de Montes Belos, que apresentou elevada concorrência, com 54 candidatos por vaga no primeiro vestibular (ESTADO DE GOIÁs, 2016, p.467).

O que chama a atenção nessa proposta de reestruturação é que os cursos que serão substituídos são os de licenciatura, que, como destacado acima, acabaram ficando sem demanda e com vagas ociosas, fato que também deve ser atribuído às mazelas supracitadas vivenciadas pela UEG. Assim, decidiu-se pela abertura de novos cursos em 2017 (oito no total), ao invés de serem tomadas medidas para enfrentar os problemas da universidade e superar as crises que permeiam as licenciaturas.

O descortinar da realidade da UEG, numa perspectiva de reflexão e de enfrentamento dos problemas, é necessário para a superação dos problemas que se arrastaram a partir de 2019.

\subsection{O cenário de mudanças da UEG a partir do governo Ronaldo Caiado em 2019 e a crise das licenciaturas}

A eleição de Ronaldo Caiado no governo do estado de Goiás impõe novos rumos para a UEG com consequências negativas para as licenciaturas. Desde setembro de 2019, prolongando-se até 2020, o estado passa a intervir na instituição. Esse processo é instituído 


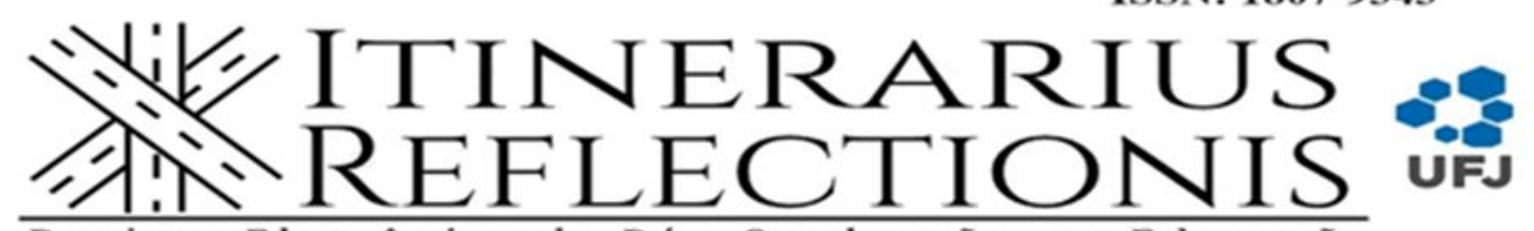

Revista Eletrônica da Pós-Graduação em Educação Universidade Federal de Jataí

Volume 17, número 4, ano 2021.

após o afastamento e renúncia do ex-reitor Haroldo Haimer, devido a supostas irregularidades junto ao Programa Nacional de Acesso ao Ensino Técnico e Emprego (PRONATEC), tendo início em março de 2019 e culminando na interinidade de um reitor indicado pelo Governo (Ivano Devilla), que renunciou seis meses depois, pontuando que "Seis meses é muito tempo para uma interinidade e a minha permanência gera ao Governo Estadual uma zona de conforto que não posso apoiar ou concordar" (DEVILLA-CARTA RENUNCIA, 2020).

Nesse contexto de turbulências e renúncias, Rafael Borges, procurador do Estado, é nomeado como reitor interino da Universidade Estadual de Goiás (UEG) pelo então governador do Estado. Para justificar tal intervenção, o governo divulgou nota responsabilizando o Conselho Superior Universitário pela ação, pontuando que o CsU da UEG "não respondeu aos desafios do descalabro administrativo em que a UEG foi jogada por anos de uso político e evidente malversação dos recursos públicos" (TRIBUNA DO PLANALTO, 2019). Assim, considerando que a UEG é uma instituição social, seus sujeitos perdem representatividade por meio do $\mathrm{CsU}$, e todas as decisões dentro da universidade ficam centralizadas nas mãos do governo por meio de seu interventor.

Com a perda de autonomia, um cenário de instabilidade, angústias e incertezas passa a fazer parte da UEG. O ano de 2020 é permeado de mudanças instituídas de cima para baixo. Isso era uma ameaça à democracia na UEG. Em um primeiro momento, há uma incerteza sobre a realização do vestibular de 2020, havendo boatos de que ele não sairia antes de uma reforma administrativa. Ainda, atendendo à ação judicial, a UEG rescinde os contratos temporários com aproximadamente 47\% dos técnicos e professores em dezembro de 2019.

Assim, os professores temporários que eram mantidos sem o interstício de contrato há décadas foram dispensados, e muitos cursos, principalmente de licenciatura, ficaram sem professores e técnicos administrativos para dar andamento às atividades acadêmicas, visto que muitos campi estão localizados no interior e não conseguiram novos professores para substituí-los, seja pela falta de mão de obra especializada e qualificada para trabalhar em uma universidade, seja pela baixa remuneração instituída para os novos contratos, seja pelo número insuficiente de novos contratados. Ademais, as novas normas para Processo Seletivo Simplificado (PSS) fixadas no edital de abertura de vagas para contrato n. 1 de 5 de dezembro de 2019 ampliaram ainda mais as diferenças entre os contratados e efetivos, 


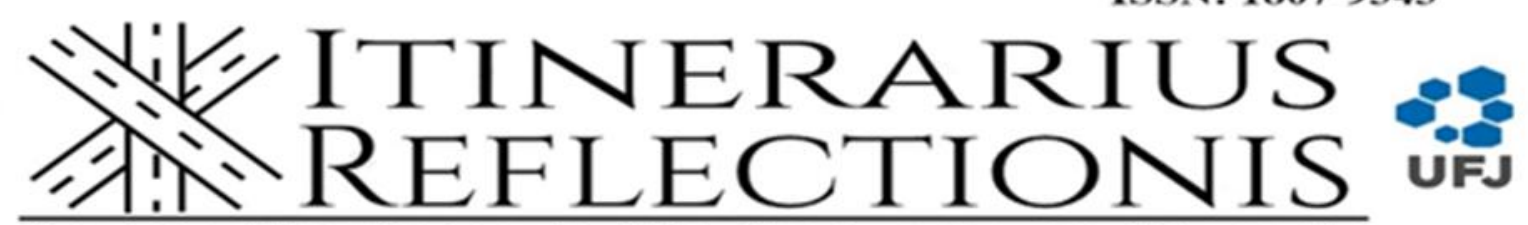

Revista Eletrônica da Pós-Graduação em Educação

Universidade Federal de Jataí

Volume 17, número 4, ano 2021.

impondo aos primeiros a ampliação da carga horária em sala, podendo chegar até a 16 horas semanais.

Como já pontuamos anteriormente, essa cultura de não rompimento dos contratos temporários criou não só a falsa expectativa de direitos, mas também o clientelismo entre os gestores e os contratados, tendo criado o chamado "cabide de emprego" e a prática do trabalho submisso, visto que, também, por anos, a UEG não tinha sequer processo seletivo simplificado, cabendo aos diretores de campus e unidades contratar e demitir quem lhes conviesse por aproximadamente 10 anos desde a criação da UEG.

Deve-se ressaltar, também, que essa situação contribuiu para a ampliação e a manutenção de cursos na UEG, pois esse alto quantitativo de professores e técnicos administrativos contratados estavam também na condição de mão de obra "barata", pois eram, em sua maioria, especialistas, e horistas, atuando praticamente apenas no ensino, não podiam - no casos daqueles que só tinham especialização - fazer pesquisa, e, por não serem efetivos, não podiam concorrer às propostas e programas de agências nacionais (PIBID, PROEXT e outras), ainda, não estavam no mesmo regime de trabalho que os efetivos, logo, não faziam parte do plano de carreira dos mesmos. Embora, em função do seu alto quantitativo, fossem mantenedores de muitos cursos, eles concorriam para diminuir a nota do curso na avaliação do Enade. Era um contrato precarizado, seja pelas péssimas condições de trabalho, seja pela sujeição a uma condição degradante de diferenciação salarial e de plano de carreira. Esse cenário também corroborava para que as licenciaturas na UEG não atendessem aos objetivos mínimos para a formação de professores, fator que denuncia o descaso com essa modalidade de ensino.

Nesse contexto de turbulências, as licenciaturas continuam sendo um dos principais "empecilhos" na UEG, então começam a ser alvo do debate sobre o fechamento de cursos. Até esse momento já havia, no mínimo, quatro relatórios sobre a reestruturação da UEG e o fechamento de cursos era um dos principais pontos de conflito.

O ANDES publicou uma nota titulada de "Reitoria da UEG deverá fechar 23 cursos de graduação - licenciatura em 13 campi e deixar cerca de 200 professores sem emprego". Nessa nota de 06 de novembro de 2019, era pontuado que "a proposta da Reitoria da Universidade Estadual de Goiás é fechar aqueles cursos que têm apresentado baixa 


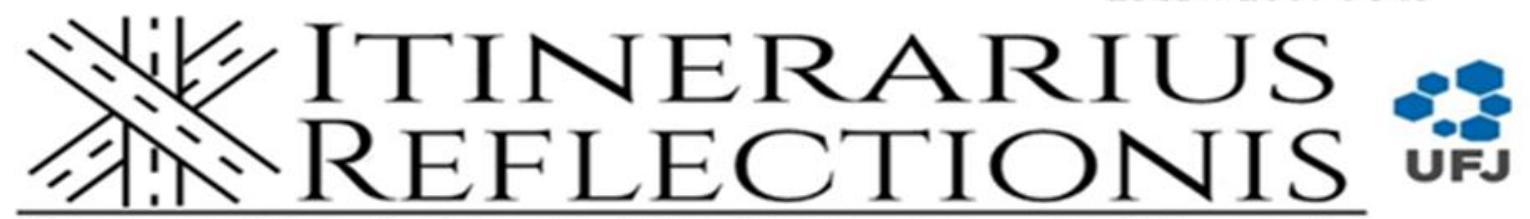

Revista Eletrônica da Pós-Graduação em Educação

Universidade Federal de Jataí

Volume 17, número 4, ano 2021.

demanda no processo seletivo da universidade". Na lista de cursos apresentada, quatro são de Geografia (ANDES, 2020)

Mas as turbulências não terminam e, em dezembro de 2019, é instituída a Reestruturação Administrativa (Lei $n^{\circ}$ 20.748) que culmina em uma série de mudanças de cima para baixo. Nesse contexto, está a formação dos institutos, sendo eles: Instituto de Educação e Licenciatura; Instituto de Ciências da Saúde; Instituto de Ciências Tecnológicas; Instituto de Ciências Sociais Aplicadas; Instituto de Ciências Agrárias. Assim, as Pró-reitorias também perderam parte de sua autonomia.

Ainda, houve o enxugamento dos campi, que passaram de 41 para 8 (Metropolitano, Central, Norte, Nordeste, Cora Coralina, Oeste, Sudoeste e Sudeste). Os outros passaram a ser Unidades Universitárias subordinadas a determinados campi. Ao que tudo indica, um dos critérios para essa subordinação foi o da localização e proximidade com determinados campi (Figura 1).

É preciso lembrar que esse debate já existia na comissão de redesenho da UEG e, conforme Relatório $\mathrm{n}^{\circ}$ 1/2019 da mesma, havia critérios para o enxugamento dos cursos e dos campi como, dentre os quais quantitativo de professores efetivos, sede própria, presença de pós-graduação e outros. Logo, deve-se considerar que esse trabalho exaustivo da comissão corroborou tal fato. Não bastasse tal proposta, ainda houve consulta aos campi sobre o processo. A pergunta que incomodava era: qual era o objetivo desse redesenho? Seria o fechamento gradativo das Unidades Universitárias/campi que abrigavam as licenciaturas? Por que a consulta sobre tal ato? Seria para legalizar o que não era legítimo?

Figura 1: Reconfiguração espacial dos campi da UEG no ano de 2020. 


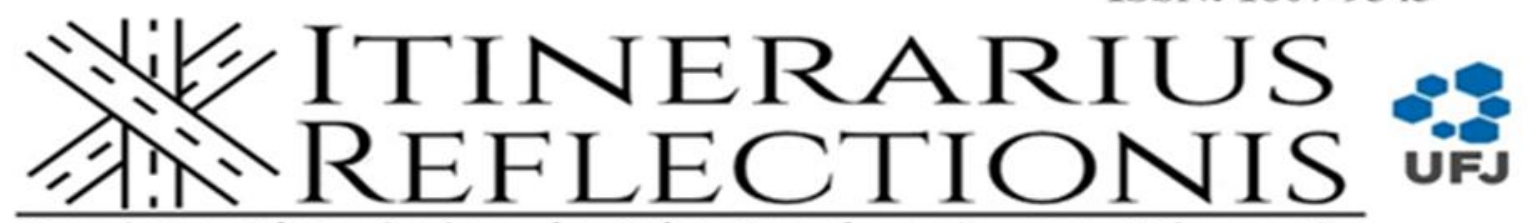

Revista Eletrônica da Pós-Graduação em Educação

Universidade Federal de Jataí

Volume 17, número 4, ano 2021.

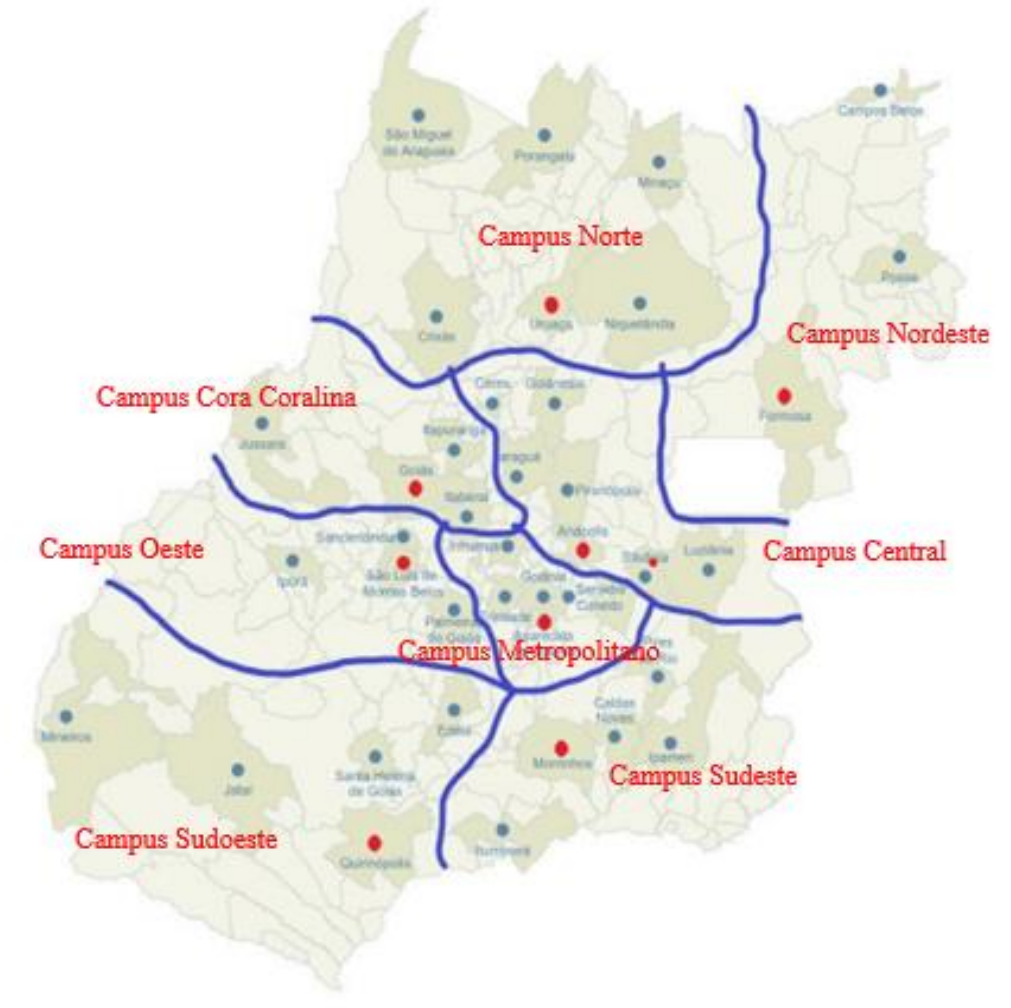

- Sede do Campus

- Unidade Universitárias ligadas ao campus de sua jurisdição

Fonte: Reforma administrativa principais pontos em 2020. Disponível em:< http://cdn.ueg.edu.br/source/universidade_estadual_de_goias_306/noticias/51900/Apresentaca o Reforma_Administrativa.pdf> Acesso em:15 de maio de 2020. Adaptação: Francilane E. de Souza 2020.

O Conselho Universitário, que havia sido destituído de poderes, passa por uma reestruturação também, passando a ter 42 membros. É instituído o Conselho de Gestão e de Curadores. Fato é que a reforma administrativa deixou muitas perguntas sem respostas. Dentre elas, o destino dos Núcleos Estruturante dos Cursos (NDE), os colegiados de cursos e a figura de um novo coordenador central de campus e dos cursos, além da figura de um coordenador institucional, dentre outras mudanças que não ficaram claras na citada reforma, afinal vieram sem consulta e aprovação da comunidade acadêmica, e eram uma ameaça às licenciaturas.

Em fevereiro de 2020, o ex-pró-reitor de graduação da UEG (Valter Gomes 


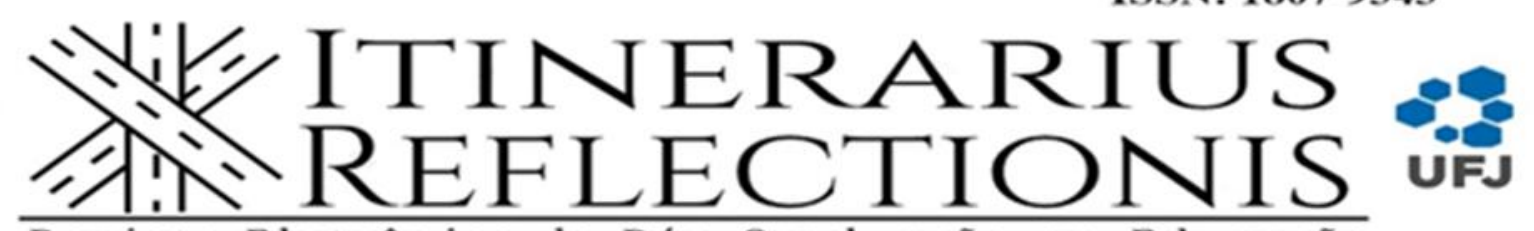

Revista Eletrônica da Pós-Graduação em Educação Universidade Federal de Jataí

Volume 17, número 4, ano 2021.

Campos) assume interinamente a função de Reitor indicado pelo governo do estado, com a promessa de que ele ficaria até a realização das eleições, previstas para o mês de novembro, e a consequente posse do reitor eleito. Outro fato que chama a atenção foi a indicação do Diretor do instituto de Licenciatura. Esse instituto passa a ser dirigido por um servidor da Secretaria Estadual de Educação, Cultura e Esporte de Goiás (SEDUCE) com pouquíssima experiência em gestão universitária e sem qualquer vivência na UEG. O governo do estado indicou alguém de fora do quadro de efetivos da UEG para dar uma nova roupagem às licenciaturas na UEG ou para varrer as mesmas por meio de seu fechamento. Nesse período, há várias manifestações por meio de cartas abertas, por meio de conclamação da reorganização dos sindicatos dos professores, mas fato é que a "mão pesada" do mandonismo e do coronelismo recai sobre a Universidade Estadual de Goiás, ferindo o princípio constitucional - Constituição Federal de 1988, artigo 207 - sobre a autonomia da Universidade e, mais que isso, ferindo o direito de uma universidade pública, mantida pelo sujeito público que defende a democracia. Ante uma proposta de governo atrelada ao neoliberalismo, cursos de licenciaturas são fardos pesados, visto que estas estão distantes dos propósitos produtivos do mercado de trabalho.

O ano de 2020 na UEG foi se estabelecendo em meio a uma pandemia (COVID19) e em meio ao caos acadêmico instituído pela reforma administrativa e pelo novo estatuto da UEG por meio de decreto (DECRETO No 9.593, DE 17 DE JANEIRO DE 2020). Assim, há destituição do NDE dos cursos em substituição a um NDE centralizado, por meio da portaria CsU n. 974 de 13 maio de 2020. No NDE, cada curso acabou sendo representado pelo coordenador institucional ou por um membro indicado pelo curso. Os colegiados que antes eram constituídos pelos docentes do quadro de cada curso foram dissolvidos em favor de um colegiado formado pelos coordenadores institucionais e o coordenador central de cada curso, fato que vem provocando a ineficiência pedagógica e a perda de autonomia didática dos cursos de licenciaturas, como pontuaremos nas seções seguintes.

A figura do colegiado de curso pontuado na nova reforma administrativa, até o mês de dezembro de 2020, não havia sido considerada como perspectiva para as tomadas de decisão, visto que elas estavam sendo instituídas de cima para baixo. Parece que esse novo colegiado passa a ter papel burocrático e "mítico" e, embora conste no artigo 82 do novo 


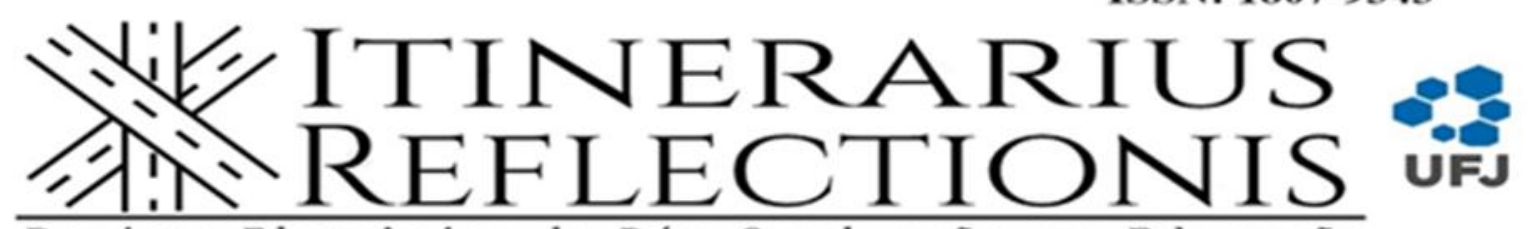

Revista Eletrônica da Pós-Graduação em Educação

Universidade Federal de Jataí

Volume 17, número 4, ano 2021.

regimento interno da UEG as atribuições deles, não apresentam qualquer força nas tomadas de decisões dos cursos. Esse novo colegiado se confunde, ainda, com o papel do NDE, visto que os mesmos membros iriam constituir tal espaço também.

Dentre as mudanças, podemos também citar o "super" vestibular da UEG que ocorreu em 2020 e foi crucial para alavancar o fechamento de cursos de licenciatura, assim como os de Geografia, tomando para tal fim, dentre outros, índices como os do Enade. Nesse contexto, os candidatos, embora optando no período da matrícula no vestibular por determinado curso e campi, após aprovação não puderam escolher os campi para cursar sua graduação, pois foi pontuado no edital de vestibular que:

A UEG suspenderá a oferta de vagas dos cursos: 11.1 que tiverem o número de inscritos inferior ao total de vagas geral, acrescido de $20 \%$ (vinte por cento). 11.2 que se enquadrarem nas situações previstas na Resolução CsU/UEG n. 804, de 29 de março de 2017, alterada pela Resolução CsU/UEG n. 922, de 31 de outubro de 2018 (GOIÁS, 2019, p.5).

Concordamos com Silva e Silva (2020, p. 299) que alertou sobre o caráter desse vestibular: "Na prática, o edital é uma foice de dois gumes que corta na ida e na volta: corta cursos e por sua vez cortará campus”. Na resolução CsU n.922 de 2018, fica estabelecido que “Art. $1^{\circ}$ Suspender a oferta de vagas no processo seletivo do curso de graduação da UEG que se enquadrar em uma das situações abaixo: [...] II - obtiver 2 (duas) vezes seguidas conceito menor ou igual a 2 (dois) no Conceito Preliminar do Curso (CPC) e no Enade”. Em 2019 a UEG tinha 5.035 vagas; mas o vestibular para o mesmo período de 2020 teve 3.694 vagas. Os cursos de licenciatura foram os principais alvos do fechamento, totalizando 21 cursos, sendo que os de Geografia, com sede em Minaçu e Itapuranga, não abriram turma e certamente serão gradativamente fechados sem qualquer mecanismo de escuta, de debate e reflexão sobre o papel das licenciaturas junto à comunidade acadêmica desses cursos.

Nesse contexto de fechamento de cursos, os ENADES tiveram papel decisivo, na medida em que vêm assumindo a função de controle e de regulação das Instituições de Ensino Superior, sendo utilizados na UEG para acelerar o fechamento dos cursos de Licenciatura.

\subsection{Caráter dos ENADES aplicados no curso de Licenciatura de 2005 a 2017}




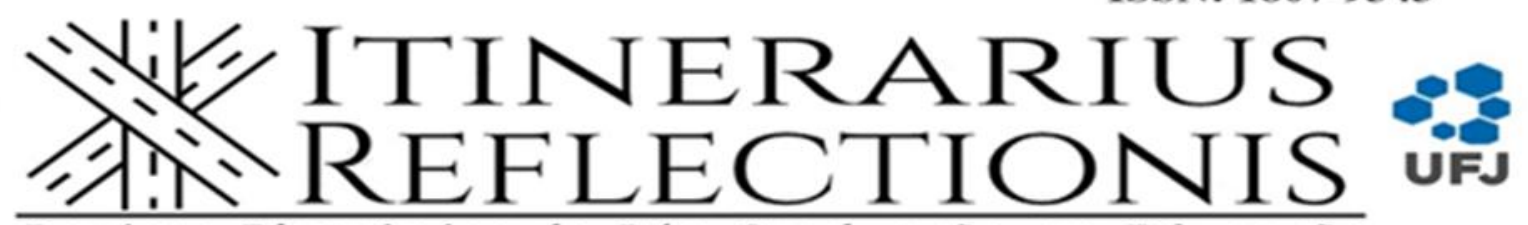

Revista Eletrônica da Pós-Graduação em Educação

Universidade Federal de Jataí

Volume 17, número 4, ano 2021.

Como já pontuamos, devemos vislumbrar o Enade dentro de um contexto dos marcos regulatórios dos cursos superiores no Brasil. Precisamos entender qual é de fato a sua função no Brasil e na UEG. O Enade inicia em 2004 e, ao longo dos anos, apresenta perspectivas, caráter e objetivos distintos. Em 2011, objetivava:

[...] aferir o desempenho dos estudantes em relação aos conteúdos programáticos previstos nas diretrizes curriculares do respectivo curso de graduação, às suas habilidades para ajustamento às exigências decorrentes da evolução do conhecimento e às suas competências para compreender temas exteriores ao âmbito específico de sua profissão, ligados às realidades brasileira e mundial e a outras áreas do conhecimento (RELATÓRIO ENADE 2008, p.2).

Por si só esses objetivos supracitados já mereceriam análise acurada quanto a sua propositura, visto que não havia indicativos claros de uma avaliação com vistas a melhorar o desempenho dos cursos. Não basta apenas avaliar, é preciso estabelecer também dispositivos legais que garantam de fato a superação dos problemas por meio de ação da instituição de ensino, apontados nesse tipo de avaliação. Ademais, cada curso possui especificidades em seus Projetos Pedagógicos, logo, sem seus programas de ensino, isso concorre para dificultar o processo de avaliação no Enade de forma justa e igualitária.

A partir de 2013, o Enade sofre algumas modificações e passa a dar ênfase para:

[...] compor o perfil dos participantes, integrando informações do seu contexto às suas percepções e vivências, e a de investigar a capacidade de compreensão desses estudantes frente à sua trajetória no curso e na Instituição de Educação Superior (IES), por meio de questões objetivas que exploraram a função social da profissão e os aspectos fundamentais da formação profissional (RELATÓRIO ENADE, 2014, p.4).

Outra característica distinta dos outros anos foram as novas perspectivas de avaliação apontadas, que se consubstanciaram em:

[...] (i) um relatório específico sobre o desempenho das diferentes áreas na prova de Formação Geral; (ii) uma análise do perfil dos coordenadores de curso; (iii) uma análise sobre a percepção de coordenadores de curso e de estudantes sobre o processo de formação ao longo da graduação; (iv) uma análise do desempenho linguístico dos concluintes, a partir das respostas discursivas na prova de Formação Geral (RELATÓRIO ENADE, 2014, p.4). 


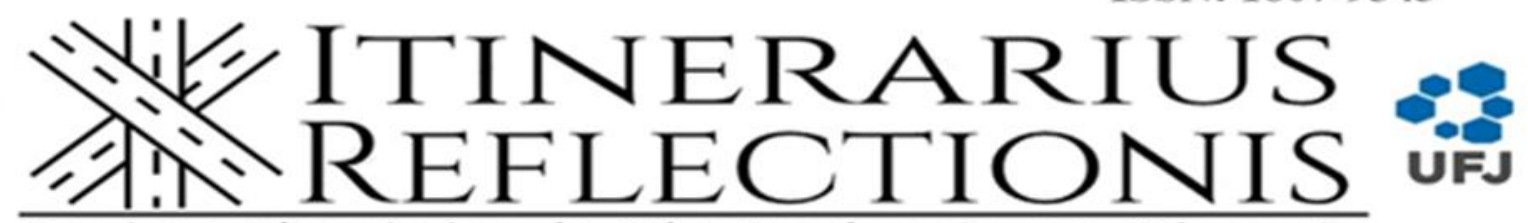

Revista Eletrônica da Pós-Graduação em Educação

Universidade Federal de Jataí

Volume 17, número 4, ano 2021.

Sobre essas mudanças, concordamos com Amaral e Samaridi (2014), que pontuam:

[...] b) na forma como se apresenta o exame, em Formação Geral e em Conteúdo Específicos, não se consegue levantar os aspectos performativos imbricados no processo de ensino-aprendizagem, ou seja, o exame não consegue medir a condição potencial preexistente de poder de execução de determinados conteúdos (AMARAL; SAMARADI, 2014, p. 7).

Considerando então que, no Brasil, o Enade não demonstrou eficiência no processo de qualificar os cursos superiores, numa perspectiva de superação de seus possíveis problemas, este passou a receber diversas críticas, dentre as quais podemos citar:

- “O exame padronizado pode, assim, restringir a amplitude do currículo, a inovação e a capacidade de resposta às mudanças nas circunstâncias" (RELATÒRIO OCDE, 2018, p. 120). Percebe-se que isso, de fato, pode se tornar um estrangulador do currículo dos cursos de graduação, visto que os mesmos acabam tentando adequar seus currículos às DNCs que, por sua vez, também costumam ter perspectivas amplas para sua aplicação, o que resulta em dificuldade para a constituição de um Enade equânime.

- Ainda, foi pontuado: “Um exame como o ENADE só pode avaliar uma pequena proporção do que se espera que os alunos aprendam durante a duração do seu programa”. (RELATÓRIO OCDE, p.12. 2018). Com essa afirmação, coloca-se a seguinte questão: se esse mecanismo de avaliação não consegue dar conta de avaliar toda aprendizagem, por que o mesmo é tomado na UEG como instrumento para determinar qual curso deve fechar?

- Distorção da noção de avaliação: ao invés de avaliar os problemas para suprimi-los, ele ranqueia as melhores universidades para beneficiá-las com mais investimentos e acaba punindo os cursos e universidades com piores notas (ANDES, 2014). Ainda, “desconsidera contextos sociais e regionais, porque sua nota é utilizada pelas empresas da educação para publicidade e, inclusive, para justificar aumento de mensalidades" (ANDES, 2014, p.2).

Podemos apontar, ademais, outros problemas como o fato de que não é possível afirmar que um curso está "abaixo da média" ou "acima da média", mas que ele é melhor ou 


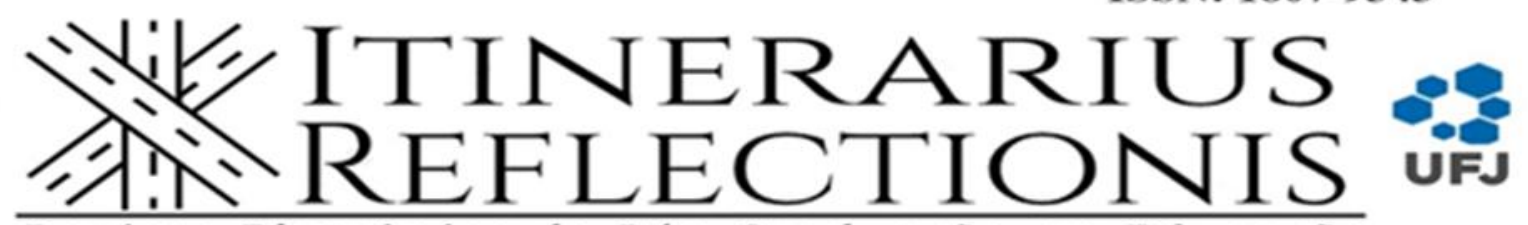

Revista Eletrônica da Pós-Graduação em Educação

Universidade Federal de Jataí

Volume 17, número 4, ano 2021.

pior do que outros.

Na UEG, o Enade foi tomado como ferramenta isenta dos problemas supracitados e, assim, foi instituído, em um primeiro momento, o não retorno de cursos que estavam suspensos devido à nota 1 (CPC/Enade), conforme Resolução CsU n. 804/2017. Dentre os critérios para definir o encerramento dos cursos, figurava justamente o ENADE:

[...] a Comissão, com base nos outros critérios estabelecidos, definiu a seguinte ordem de preferência para verificação de qual curso permaneceria em cada região (ordem hierárquica de critérios, ou seja, o primeiro critério se sobrepõe ao segundo): A) Não retorno dos cursos suspensos com nota 1 no Enade; B) Proporção dos seguintes critérios: Taxa de ocupação (Anexo 1); Taxa de sucesso (Anexo 2); Enade contínuo[2] ; CPC contínuo[3] ; Demanda (candidato por vaga) (Anexos 3 e 4); Proporção de docente efetivo do Câmpus (Anexo 5) (GOIÁS, 2019, p. 5).

Embora os relatórios de redesenho da UEG apontassem múltiplos fatores para o encerramento de turmas em cursos de Graduação, o Enade foi se constituindo como um dos indicadores mais preocupantes, e, em alguns momentos, nas narrativas daqueles que ocupavam as administrações dos campi da UEG, as notas do Enade eram consideradas preponderantes no fechamento de cursos, de modo a atribuir aos professores grande parte do insucesso das notas. Se observarmos o CPC e o grau de responsabilidade da Universidade na constituição dessa nota, ele praticamente não foi considerado na decisão de fechamento de cursos, sendo que a baixa inscrição nos vestibulares também está associada a um CPC com nota baixa, pois este pode influenciar um curso de graduação pouco atraente, logo, com baixa procura.

Na UEG, ao longo do ano de 2020, também foram instituídas mudanças administrativas e medidas pedagógicas que contribuíram para acelerar ainda mais a precarização e, portanto, o fechamento dos cursos de licenciatura de Geografia, pois:

Na prática, os campi que agora foram considerados inaptos a ofertar cursos e a se manter no mapa da educação superior - estadual, pública e gratuita - no Estado de Goiás, foram anteriormente e sucessivamente abandonados, e em decorrência dessa falta de investimento, tiveram notas baixas no Enade e outras implicações do não investimento e valorização (SILVA; SILVA. 2020, p.296). 


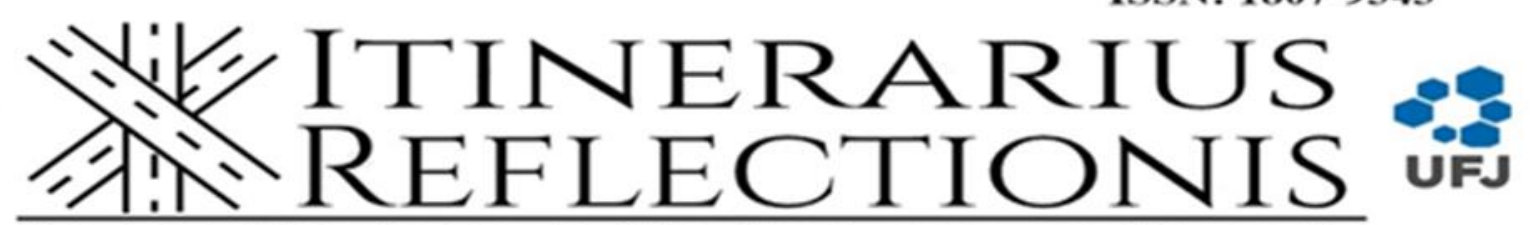

Revista Eletrônica da Pós-Graduação em Educação Universidade Federal de Jataí

Volume 17, número 4, ano 2021.

Essa crise na UEG pode ser definida principalmente pela perda de autonomia da Universidade, entre cujos pilares está a autonomia didática, que foi prejudicada pelas mudanças pedagógicas vindas de cima para baixo.

\subsection{Consequências pedagógicas da reforma administrativa na UEG e nos cursos de Geografia}

No ano de 2020, em plena pandemia da COVID 19, a UEG, por meio do instituto de Licenciatura, determinou, nos Núcleos DE dos cursos de Licenciatura, a obrigação de unificação de matriz, alegando dificuldade na realização do vestibular caso não houvesse essa unificação. No entanto, como já foi apontado anteriormente, com a reforma administrativa, os NDEs deixaram de ser constituídos em cada curso de graduação para serem formados por membros de todos os cursos com a mesma formação. Então, nesse processo, os 10 cursos de Geografia passam a ter um único NDE e um único colegiado.

Nos poucos mais de 20 anos de existência da UEG, alguns cursos de licenciatura já adotaram, no mínimo, quatro matrizes curriculares com mudanças e/ou alterações, como o de Geografia (1999-inicial, 2004, 2009 e 2015, que é a atual), que está a caminho da quinta matriz, sendo a de 2004 com unificação entre os cursos, a de 2015 sem unificação e, agora, com proposta de unificação novamente para 2021. Por si só, isso revela a necessidade de debate sobre o tema, tendo em vista a dificuldade de formar duas turmas de professores na mesma matriz e, acima de tudo, de dar continuidade a um projeto democrático de formação de professores, visto que quase sempre essas mudanças de matrizes estão sendo instituídas de cima para baixo. Pode ocorrer ainda a evasão, uma vez que o aluno que tranca o curso ou é reprovado tem que se adequar à nova matriz, elevando assim o tempo para integralizar a mesma e concluir o curso. Pode ocorrer também o aumento de investimento com capital humano, com a necessidade de tutorias para os alunos que ainda têm que cursar disciplinas que foram extintas.

Outra questão é: o que está sendo imposto é uma matriz ou uma grade curricular? Matriz curricular é proposta pelo curso para o curso, com a participação dos sujeitos que irão executar a mesma, enquanto a grade, como o próprio nome já diz, engessa, vem de cima para 


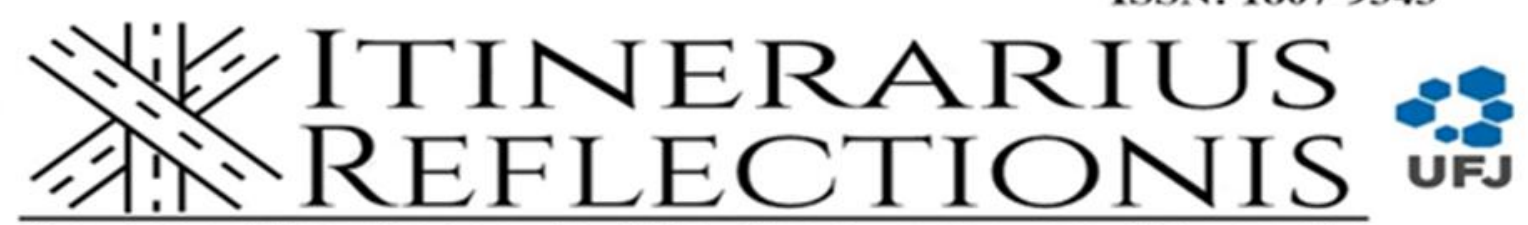

Revista Eletrônica da Pós-Graduação em Educação Universidade Federal de Jataí

Volume 17, número 4, ano 2021.

baixo, é rígida e não deixa margem para adaptações, dificilmente possibilitando êxito no processo de ensino-aprendizagem, pois a tradição pedagógica nos ensina que um Projeto de Curso só tem êxito quando construído pelos sujeitos que irão executá-lo, sendo a própria construção um ato educativo. Ainda, essa unificação não foi precedida da construção de um Projeto Político Pedagógico. Como construir uma matriz unificada sem o debate, justo e necessário, sobre, dentre outras reflexões, qual concepção de curso adotar ante a sociedade contemporânea?

Outro fato que merece reflexão é a unificação da matriz com um NDE centralizado para todos os cursos. Quais são de fato as implicações disso? Seria a redução dos cursos de forma gradual? Essa "grade" unificada em conjunto a um único NDE e um "super" vestibular para todos os campi não facilitará o fechamento de cursos autorizado por essa estrutura? Ainda, será que esse NDE não será instrumento para dar legalidade a tal fato? Não seria necessário e justo lutar pela autonomia dos cursos por meio de matriz que refletisse as especificidades dos cursos e por um NDE descentralizado cuja função é estruturar o curso?

Outro fato preocupante é a coordenação de curso centralizada e a perda das coordenações adjuntas de estágio, pesquisa e de extensão. Nos campi, as funções dessas coordenações adjuntas não estão claramente definidas em resoluções, sobre qual outro cargo irá de fato incorporá-las. Ademais, como um coordenador que está também acumulando a função de docente conseguirá coordenar mais de um curso? Na geografia, o coordenador central tem que coordenar 10 cursos distribuídos nas cinco mesorregiões do estado de Goiás.

Essas medidas demonstram que a universidade está perdendo autonomia didática, uma vez que esta “[...] consiste na liberdade de ensinar e aprender e está baseada no reconhecimento da competência da universidade para definir qual conhecimento é relevante e como deve ser transmitido" (DURHAM, S/D, p.6.). Todas essas ações - NDE, colegiado e coordenação de cursos centralizados - vêm se colocando em um contexto de truculência, mandonismo e autoritarismo, pois o Conselho Universitário da UEG, ao ser destituído de seus poderes, apoderou ainda mais o governo do estado, que impeliu seus ditames à UEG. As medidas que vêm sendo tomadas configuram-se como instrumento da desestruturação dos cursos já fragilizados, colocando as licenciaturas como alvo das políticas de fechamento de cursos na UEG. 


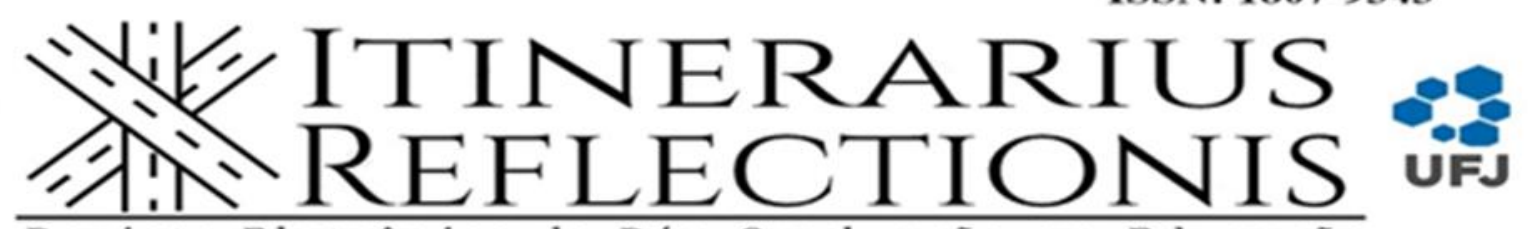

Revista Eletrônica da Pós-Graduação em Educação Universidade Federal de Jataí

Volume 17, número 4, ano 2021.

\section{CONSIDERAÇÕES FINAIS}

A Universidade é uma instituição social e, por isso, ela deve ser pensada e constituída por e a partir dos sujeitos com ela envolvidos, de modo que sua materialidade se dê a partir das ações desses sujeitos. Ela está em constante movimento, muda o mundo, muda a Universidade; muda a cultura, muda a Universidade; novos e velhos paradigmas vão se confrontando em um espaço em movimento e de conflito.

Na UEG, é notório que nos últimos anos vem se consubstanciando a perda de autonomia universitária, por meio de medidas dos governos "marconista" e "caiadista" para implementar ora a expansão da universidade dentro de uma política eleitoreira, ora a política de encolhimento da mesma com o fechamento dos cursos de licenciatura, numa perspectiva que vê a universidade como uma organização que onera os cofres do estado de Goiás.

Nesse processo, ora é a mão invisível de um governo que decide ampliar os campi e cursos de graduação na UEG, sem consulta à comunidade acadêmica, ora é a mão pesada de outro governo ceifando o direito à educação, com fechamento dos campi e de cursos na UEG. Os cursos de licenciatura se tornaram principal alvo de fechamento. A interiorização da universidade passa a ficar ameaçada pelo discurso de que os cursos não atendem mais às demandas da sociedade. Abastecidos somente com quadro negro e giz, os cursos de licenciaturas vêm lutando há anos para continuar cumprindo sua função social.

A participação da comunidade acadêmica no direito às tomadas de decisão na UEG sempre foi luta constante. Manifestações, greves, movimentos em defesa dessa universidade, mobilização e retomada do sindicato dos docentes da UEG sempre foram espaços de lutas. Ainda assim, nesses últimos dois anos, essa instituição vem se desmantelando e perdendo território em função de ações autocráticas do governo, tendo como consequência a perda total de democracia. $\mathrm{O}$ mandonismo e a truculência do governo Caiado atropelaram até mesmo a autonomia didática dos cursos de graduação.

A comunidade acadêmica, junto ao povo goiano, precisa recuperar o seu lugar de fala e de tomada de decisão na UEG, pois como nos lembra o poema de Eduardo Alves da Costa "Na primeira noite eles se aproximam e roubam uma flor do nosso jardim. E não 


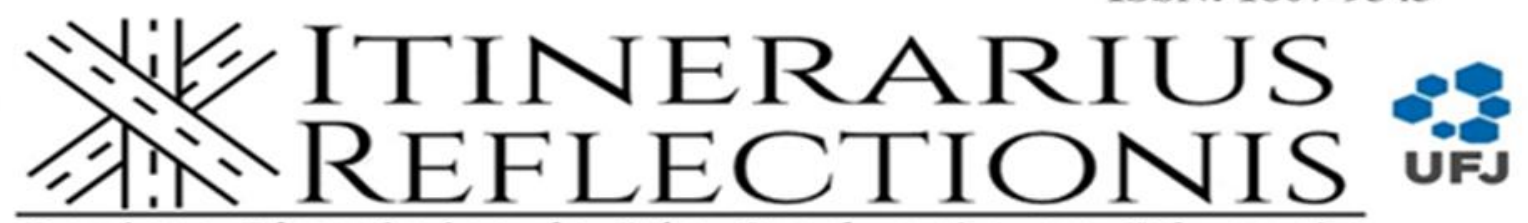

Revista Eletrônica da Pós-Graduação em Educação

Universidade Federal de Jataí

Volume 17, número 4, ano 2021.

dizemos nada. Na segunda noite, já não se escondem: pisam as flores, matam nosso cão, e não dizemos nada. Até que um dia, o mais frágil deles entra sozinho em nossa casa, rouba-nos a luz e, conhecendo nosso medo, arranca-nos a voz da garganta. E já não podemos dizer nada”.

Esta é uma instituição social que se consubstancia dentro de políticas de direito à educação e não pode ficar à mercê de políticas de governo. É uma instituição pública que deveria estar atrelada às políticas de garantia e de ampliação ao direito à educação pública, gratuita, de qualidade e de acesso a todos.

\section{REFERÊNCIAS}

ANDES. Nota Pública da Diretoria do ANDES sobre o ENADE. Disponível em:< http://portal.andes.org.br/>. Acesso em: 20 de set. de 2020.

AMARAL; E. A. I. SAMARADI. A conversão do Enade em instrumento de regulação da educação superior e sua interferência na gestão do curso de administração da Universidade Estadual de Goiás. Didática e Prática de Ensino na relação com a Sociedade. Disponível em: http://www.uece.br/endipe2014/index.php/2015-02-26-14-09-

14?limit=5\&start=1550pdf.. Acesso em: 10 de mai. de 2020.

CHAUI, M. A Universidade pública sob nova perspectiva. Revista brasileira de educação. Set /Out /Nov /Dez 2003 No 24. Disponível em: https://www.scielo.br/pdf/rbedu/n24/n24a02.pdf. Acesso em: 20 de mar. De 2020.

CONSTITUIÇÃO DA REPÚBLICA FEDERATIVA DO BRASIL de 1988. Brasília, DF: Presidência da República, [2016]. Disponível em: http://www.planalto.gov.br/ccivil_03/Constituicao/Constituiçao. Acesso em: 20 de dez. de 2019.

DEVILLA, I. Carta Renúncia. Disponível em: https://www.jornalopcao.com.br/bastidores/ivano-daville-renuncia-ao-cargo-de-reitor-da-ueg211213/.. Acesso em: 15 de dez. de 2020.

DURHAM E. R. A autonomia universitária: o princípio constitucional e suas implicações. Disponível em: http://nupps.usp.br/downloads/docs/dt8909.pdf. Acesso em: 11 de dez. de 2020.

ESTADO DE GOIÁS.DECRETO No 9.593, DE 17 DE JANEIRO DE 2020. Disponível em:< https://legisla.casacivil.go.gov.br/pesquisa_legislacao/72508/decreto-9593>. Acesso em: 20 de fev. de 2020. 


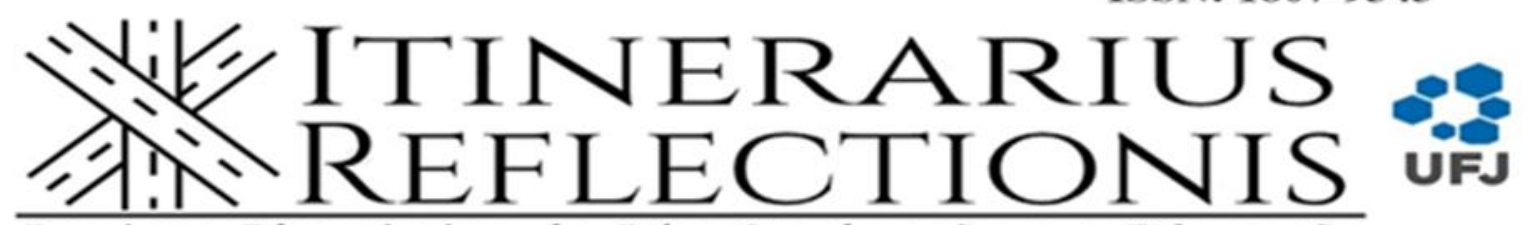

Revista Eletrônica da Pós-Graduação em Educação

Universidade Federal de Jataí

Volume 17, número 4, ano 2021.

FAVERO, M. de L. A. Universidade e estágio curricular: subsídios para a discussão. In: ALVES, N. (Org). Formação de professores: pensar e fazer. São Paulo: Cortez, 2004.

GOIÁS. Edital de abertura do vestibular da UEG. Disponível em:

http://www.nucleodeselecao.ueg.br/pdfs/processos/250/Edital\%20de\%20abertura\%20retificad o.pdf.. Acesso em: 08 de out. 2019.

UEG. Resolução CsU 922 de 2018. Disponível em:

<http://www.legislacao.ueg.br//exec/consulta_tipo_doc_legislacao/?funcao=lista_tipo_doc_le gislacao \&variavel $=27 \&$ tipo $=\mathrm{CsU} \& \mathrm{ano}=2017$ \&origem $=\& i d \_$origem $=9 \&$ page $=7$. $>$. Acesso em 20 de dez. de 2019.

Reestruturação administrativa (Lei no 20.748).Disponível em: <

http://cdn.ueg.edu.br/source/universidade_estadual_de_goias_306/noticias/51900/Reforma_A dministrativa_da_UEG.pdf $>$. Acesso em 22 de fev. de 2020.

Relatório $n^{0}$ 1/2019 colegiados- 16136/Relatório da comissão de redesenho.

Disponível em: <http://www.posse.ueg.br/cdn/redesenho/relatorio.pdf.>. Acesso em: 30 de mai. de 2020.

Reforma administrativa principais pontos em 2020. Disponivel em:<

http://cdn.ueg.edu.br/source/universidade_estadual_de_goias_306/noticias/51900/Apresentaca o_Reforma_Administrativa.pdf $>$. Acesso em:15 de maio de 2020.

CCET. Avaliação institucional. Disponível em:

<http://www.ccet.ueg.br/cliente/conteudo/avaliacao_institucional/2005/CAPITULO\%20I.pdf. $>$. Acesso em: 15 de jul. de 2020.

INEP. ENADE. Relatórios das IES. Disponível em:

http://enade.inep.gov.br/enade/\#!/relatorioIES>. Acesso em 15 de set. de 2020.

OCDE. Rethinking quality assurance for higher education in Brazil. 2018. Disponível em:< http://inep.gov.br/sinaes/relatorio-ocde>. Acesso em: 17 de jun. de 2020.

SILVA, L.N. SILVA, M. E. O mapa do retrocesso da interiorização da educação superior: a redução da universidade estadual de goiás. Formação em Movimento. v.2, i.1, n.3. p. 292308, jan./jun.2020

TRIBUNA DO PLANALTO. Disponível em:<http://tribunadoplanalto.com.br/2019/09/20/ueg-tem-novo-reitor/ > . Acesso em 15 abril, 2020 . 